Corrigendum

\title{
Corrigendum to "An Increased Ratio of Glycated Albumin to HbAlc Is Associated with the Degree of Liver Fibrosis in Hepatitis B Virus-Positive Patients"
}

\author{
Hirayuki Enomoto, ${ }^{1}$ Nobuhiro Aizawa, ${ }^{1}$ Hideji Nakamura, ${ }^{2}$ Yoshiyuki Sakai, \\ Yoshinori Iwata, ${ }^{1}$ Hironori Tanaka, ${ }^{1}$ Naoto Ikeda, ${ }^{1}$ Tomoko Aoki, ${ }^{1}$ Yukihisa Yuri, ${ }^{1}$ \\ Kazunori Yoh, ${ }^{1}$ Kenji Hashimoto, ${ }^{1}$ Akio Ishii, ${ }^{1}$ Tomoyuki Takashima, ${ }^{1}$ Kazunari Iwata, ${ }^{1}$ \\ Masaki Saito, ${ }^{1}$ Hiroyasu Imanishi, ${ }^{1}$ Hiroko Iijima, ${ }^{1}$ and Shuhei Nishiguchi ${ }^{1}$ \\ ${ }^{1}$ Division of Hepatobiliary and Pancreatic Disease, Department of Internal Medicine, Hyogo College of Medicine, \\ Mukogawa-cho 1-1, Nishinomiya, Hyogo 663-8501, Japan \\ ${ }^{2}$ Department of Gastroenterology and Hepatology, Nissay Hospital, Itachibori 6-3-8, Nishi-ku, Osaka 550-0012, Japan
}

Correspondence should be addressed to Hirayuki Enomoto; enomoto@hyo-med.ac.jp

Received 30 October 2015; Accepted 18 November 2015

Copyright ( $(2016$ Hirayuki Enomoto et al. This is an open access article distributed under the Creative Commons Attribution License, which permits unrestricted use, distribution, and reproduction in any medium, provided the original work is properly cited.

In the first sentence of Section 2.1 of "An Increased Ratio of Glycated Albumin to HbAlc Is Associated with the Degree of Liver Fibrosis in Hepatitis B Virus-Positive Patients" [1], we note that the description "between January 2008 and March 2010" should be corrected to be "between January 2008 and March 2013."

\section{References}

[1] H. Enomoto, N. Aizawa, H. Nakamura et al., "An increased ratio of glycated albumin to HbAlc is associated with the degree of liver fibrosis in hepatitis B virus-positive patients," Gastroenterology Research and Practice, vol. 2014, Article ID 351396, 6 pages, 2014. 


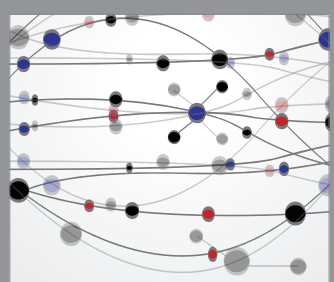

The Scientific World Journal
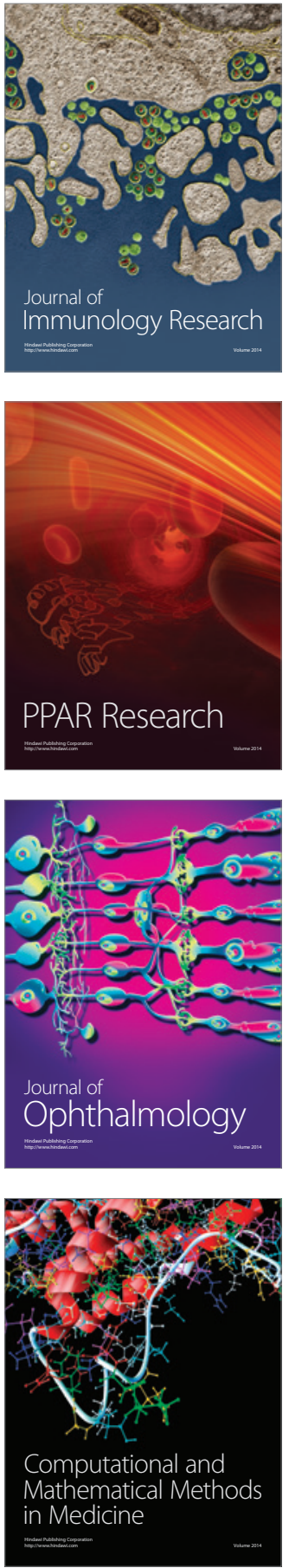

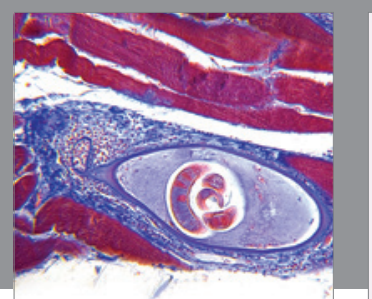

Gastroenterology Research and Practice

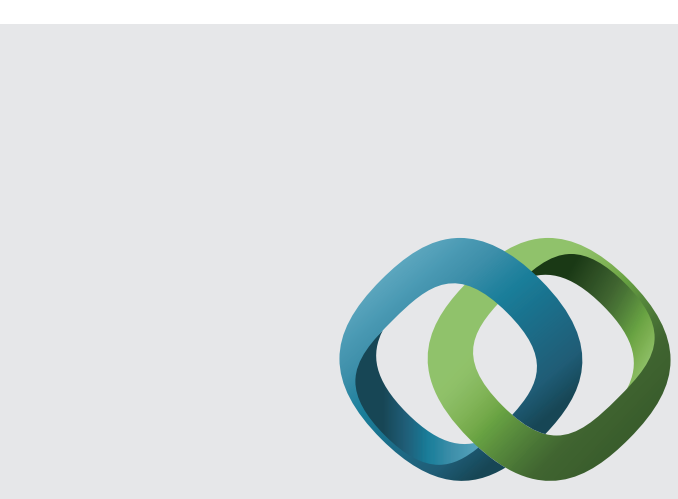

\section{Hindawi}

Submit your manuscripts at

http://www.hindawi.com
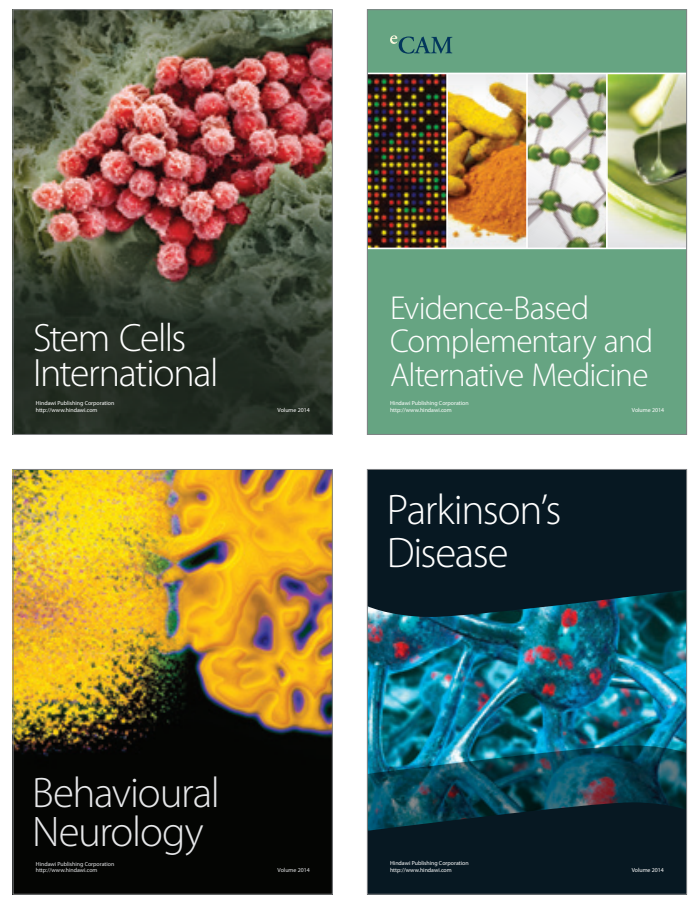
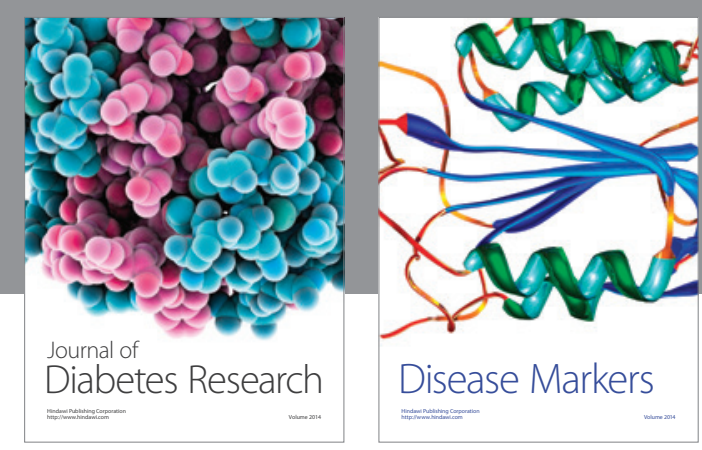

Disease Markers
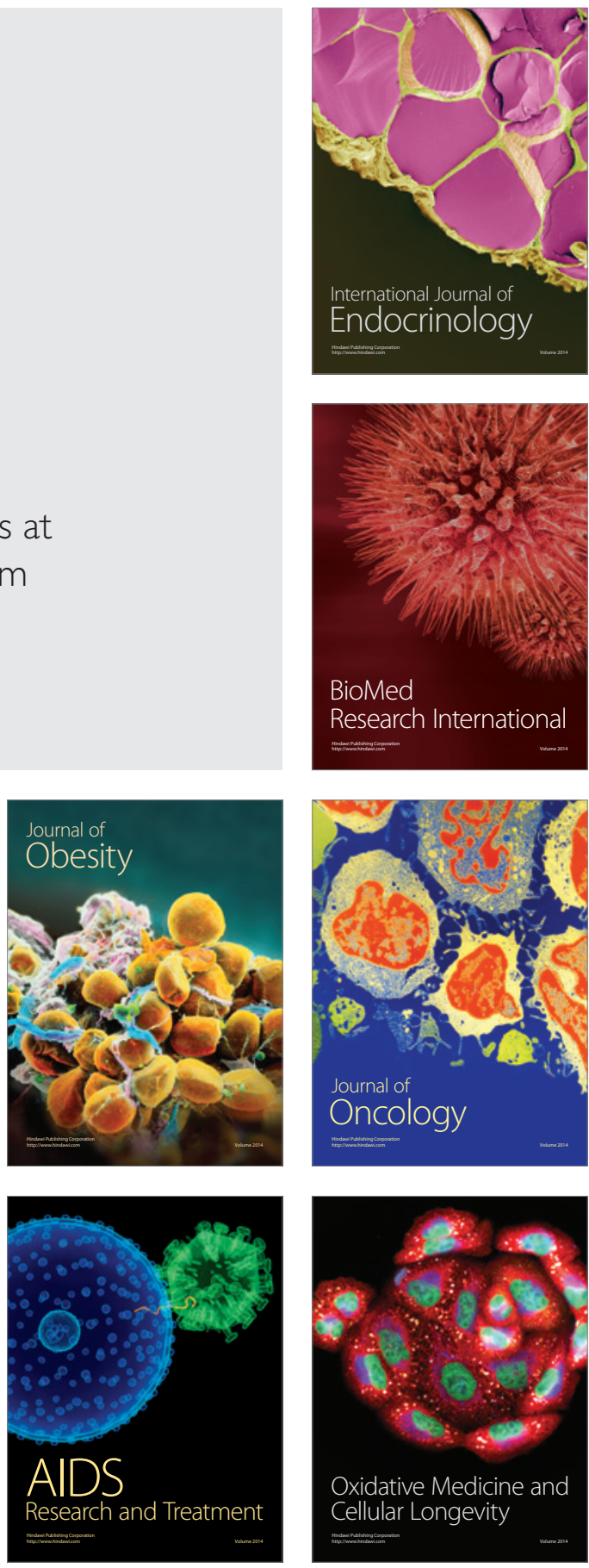